\title{
Awareness \& Knowledge of Maxillofacial Prosthodontics as a Dental Specialty amongst Medical Practitioners
}

\author{
Trupti M. Dahane ${ }^{1}$, Rupali Mukesh Patel ${ }^{2}$, Surekha Godbole Dubey ${ }^{3}$, Kashish Mangal ${ }^{4}$ \\ 1,2, 3,4 Department of Prosthodontics, Sharad Pawar Dental College, DMIMS, Sawangi, Maharashtra, India.
}

\section{ABSTRACT}

\section{BACKGROUND}

The primary goal of a medical team for managing patients suffering from tertiary disease (cancer) is to eliminate the disease or to remove the underlying pathology. Also, restoration along with rehabilitation of the defect to boost the confidence and self-esteem of the patients must be done. Rehabilitation usually is considered as a part of prosthodontics i.e., maxillofacial prosthodontics. But the scope of maxillofacial prosthodontics as a specialty does not find recognition amongst the multidisciplinary medical team in dealing with maxillofacial defects. The objective of the study was to evaluate the awareness and knowledge of the maxillofacial prosthodontics amongst medical practitioners in and around Wardha city.

\section{METHODS}

A descriptive, cross-sectional survey was conducted using a questionnaire. The validated questionnaire contained 14 questions, of which 13 were awareness based, and 1 was attitude based. It included relevant photographs. 219 medical practitioners working either in hospitals attached to educational institutes or private sector participated in the study.

\section{RESULTS}

The study reveals the percentage of medical practitioners who are aware about maxillofacial prosthodontics branch. Only $10.9 \%$ were aware about maxillofacial prosthodontics as a branch of dentistry which deals with the restoration of maxillofacial defects.

\section{CONCLUSIONS}

The survey points towards a need to conduct awareness activities to make the medical practitioners aware of this fact. This will hopefully increase the patient's referral with such defects to a maxillofacial prosthodontists or can include a maxillofacial prosthodontist as a part of multidisciplinary team that could benefit the patient for complete rehabilitation.

\section{KEY WORDS}

Prosthesis, Trauma, Defects, Rehabilitation
Corresponding Author: Dr. Trupti M. Dahane, Associate Professor, 202, Department of Prosthodontics, Sharad Pawar Dental College, DMIMS, Sawangi, Maharashtra, India.

E-mail: drtrupti.prostho@gmail.com

DOI: $10.14260 / j e m d s / 2021 / 131$

How to Cite This Article:

Dahane TM, Patel RM, Dubey SG, et al. Awareness \& knowledge of maxillofacial prosthodontics as a dental specialty amongst medical practitioners. J Evolution Med Dent Sci 2021;10(09):608-612, DOI: 10.14260/jemds/2021/131

Submission 24-09-2020,

Peer Review 30-12-2020,

Acceptance 07-01-2021,

Published 01-03-2021.

Copyright (C) 2021 Trupti M. Dahane et al. This is an open access article distributed under Creative Commons Attribution License [Attribution 4.0 International (CC BY 4.0)] 


\section{BACKGROUND}

Face has a unique role in social and emotional expression, communication and most importantly it is the reflection of oneself as expressed by St. Jerome's statement "face is the mirror of mind". ${ }^{1}$ Any defects of the face and associated structures therefore have important psychosocial implications on affected patients. Craniofacial / maxillofacial defects lead to severe depression that often require rehabilitation as "to appear human is fundamental right of every individual".2 Patients who have been traumatised in an accident and / or have had surgical removal of diseased tissues requires restoration of the function and aesthetics. Restoration in these cases should ideally be carried out as soon as possible to minimise psychological trauma. ${ }^{3}$ Surgical reconstruction is considered to be the primary treatment of choice in such cases, although, not all the defects are treatable by surgical intervention. ${ }^{4}$ It depends on multiple factors like the size, location of the defect, the loss of vital anatomical structures and general debilitation of the patient. ${ }^{5}$ An available treatment option for such cases is the prosthetic rehabilitation of the defects.

Prostheses are an artificial replacement of part of the human anatomy restoring form, function and esthetic. ${ }^{6}$ Maxillofacial prosthodontics is concerned with the restoration and / or replacement of the stomatognathic and craniofacial structures with prostheses that may or may not be removed on a regular or elective basis. Maxillofacial prosthodontists are individuals who have the knowledge and skill set to provide the service of customising a prosthesis for maxillofacial defects. $^{7}$ They should work as a part of multi-disciplinary team, generally associated with oral and maxillofacial surgeons, plastic surgeons, ear, nose and throat surgeons, ophthalmologists, general surgeons, general physicians, oncologists, orthopaedic surgeons, gynaecologists and paediatricians, speech therapists, occupational therapists, physiotherapists etc. ${ }^{4}$

The primary goal of the medical team to manage patients suffering from tertiary disease is to eliminate the disease or to remove the underlying pathology. ${ }^{8} \mathrm{But}$, the management also encompasses restoring and rehabilitating the lost tissue / defect. Rehabilitation implies to restore to former privilege, which is the essence of service provided by a maxillofacial prosthodontist who is trained to make a prosthesis to restore the functional, aesthetic and psychologic lacunae associated with the defect.

This demands collaborative participation of medical and dental practitioners in order to best address the patient's needs. It has been observed that most of the patient's in India suffering with such defects do not get referred to a maxillofacial prosthodontist and remain untreated. Primary cause for this could be that the medical practitioners like surgeons, ophthalmologists, ENT surgeons, plastic surgeons themselves may not be aware about the speciality responsible to treat such patients for the residual defects after surgery.

Such lack of awareness can deprive the patients of the benefits in spite of the existing facilities and compel him to live the remaining years with poor quality of life.

Therefore, the present study was undertaken to seek information about the awareness and knowledge of the medical practitioners in and around Wardha City towards the maxillofacial branch of dentistry as a speciality to restore maxillofacial defects.

\section{METHODS}

This descriptive cross-sectional study was conducted amongst the institutional and private medical practitioners of Wardha city, Maharashtra after institutional ethical approval by Datta Meghe Institute of Medical Sciences (DMIMS). The study duration was from January 2019 to June 2019.

Since no such type of study was found in literature, we devised a questionnaire (Copyrighted ROC Number L$94055 / 2020$ ) and got it validated. For validation, face as well as content validation was obtained from the subject experts for the questionnaire. The reliability of questionnaire was found to be Cronbach's Alpha of 0.89 .

\section{Inclusion Criteria}

1. Medical practitioners associated with hospitals or practicing individually.

2. Post-graduate residents associated with medical hospital.

The purpose and nature of the study was explained to each participant fitting in the inclusion criteria and the willing participants were requested to complete a comprehensive closed ended, self-administered questionnaire. Of 300, 219 medical practitioners willingly participated in the study.

The questionnaire contained a total 14 questions. 13 questions were knowledge based, regarding awareness about maxillofacial prosthodontics as a specialised branch, various types of maxillofacial defects and materials needed for prosthesis fabrication etc. While the last one was attitudebased question. The questions were supported with relevant photographs so that a self-explanatory unique questionnaire is made. Sample size was taken based on the conveniences of the study. Professional details of the subjects such as area of specialisation and years of experience were also recorded in the study. Frequency analysis was done using Statistical Package for the Social Sciences (SPSS) software version 22.0.

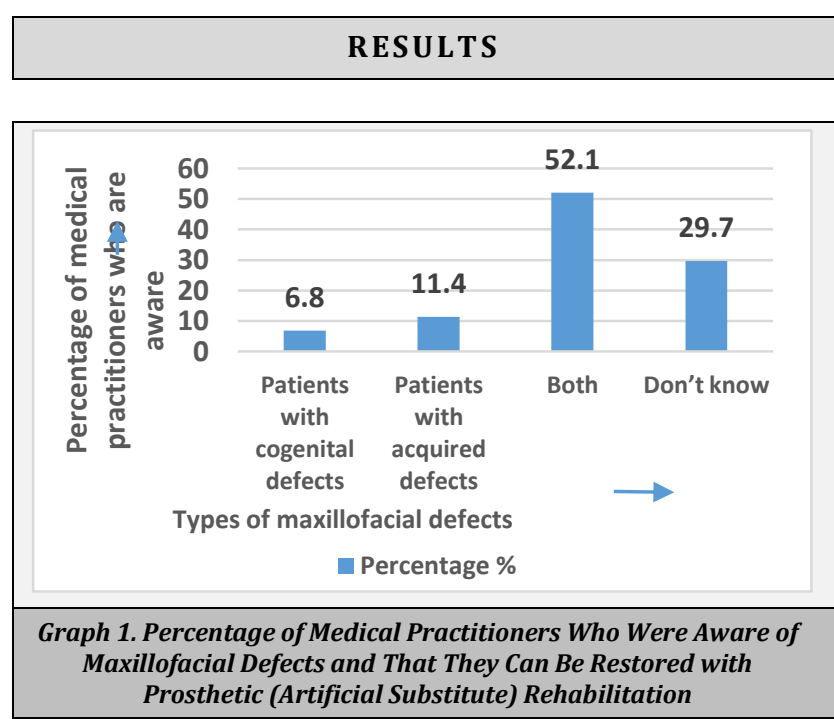




\begin{tabular}{|c|c|c|c|}
\hline & & 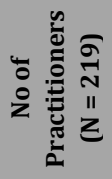 & 总 \\
\hline \multirow{4}{*}{$\begin{array}{c}\text { Do you know the different types } \\
\text { of maxillofacial defects that } \\
\text { require prosthetic (artificial } \\
\text { substitute) rehabilitation? }\end{array}$} & Patients with congenital defects & 15 & 6.8 \\
\hline & Patients with acquired defects & 25 & 11.4 \\
\hline & Both & 114 & 52.1 \\
\hline & Don't know & 65 & 29.7 \\
\hline \multirow{7}{*}{$\begin{array}{l}\text { Which of the following type of } \\
\text { prosthesis are you aware of? }\end{array}$} & Ear & 26 & 11.87 \\
\hline & Eye & 27 & 12.33 \\
\hline & Nasal \& midfacial prosthesis & 68 & 31.05 \\
\hline & Cranial prosthesis & 4 & 1.83 \\
\hline & $\begin{array}{c}\text { Prosthesis for maxilla \& } \\
\text { mandible }\end{array}$ & 93 & 42.47 \\
\hline & Finger & 8 & 3.65 \\
\hline & None & 65 & 29.68 \\
\hline \multirow{4}{*}{$\begin{array}{l}\text { If you have heard of it, where did } \\
\text { you hear about it? }\end{array}$} & Newspaper & 0 & 0 \\
\hline & Books & 69 & 31.5 \\
\hline & Dentist & 65 & 29.7 \\
\hline & Friend & 85 & 38.8 \\
\hline \multirow{2}{*}{$\begin{array}{l}\text { Have you ever come across a } \\
\text { patient with any of the above } \\
\text { mentioned defect who has been } \\
\text { rehabilitated with a prosthesis? }\end{array}$} & Yes & 58 & 26.4 \\
\hline & No & 161 & 73.5 \\
\hline \multirow{2}{*}{$\begin{array}{l}\text { Have you ever referred a patient } \\
\text { with any of the above mentioned } \\
\text { defects for rehabilitation? }\end{array}$} & Yes & 5 & 2.3 \\
\hline & No & 214 & 97.7 \\
\hline \multirow{7}{*}{$\begin{array}{l}\text { Which of the following } \\
\text { prosthesis have you referred the } \\
\text { patient for? }\end{array}$} & Ear & 1 & 0.5 \\
\hline & Eye & 2 & 0.9 \\
\hline & Nasal and midfacial prosthesis & 0 & 0 \\
\hline & Cranial prosthesis & 0 & 0 \\
\hline & $\begin{array}{c}\text { Prosthesis for maxilla \& } \\
\text { mandible }\end{array}$ & 0 & 0 \\
\hline & Any other [Finger] & 2 & 0.9 \\
\hline & None & 214 & 97.7 \\
\hline \multirow{2}{*}{$\begin{array}{l}\text { Are you aware of the fact that } \\
\text { such prosthesis can be better } \\
\text { supported and retained with the } \\
\text { help of implants? }\end{array}$} & Yes & 42 & 19.2 \\
\hline & No & 177 & 80.8 \\
\hline \multirow{2}{*}{$\begin{array}{l}\text { Are you aware of the average } \\
\text { cost which the patient will have } \\
\text { to bear for such kind of } \\
\text { prosthesis? }\end{array}$} & Yes & 0 & 0 \\
\hline & No & 219 & 100 \\
\hline \multirow{4}{*}{$\begin{array}{c}\text { What material as per your } \\
\text { knowledge is used for } \\
\text { fabrication of such prosthesis? }\end{array}$} & Acrylic resin & 29 & 13.2 \\
\hline & Silicone & 56 & 25.6 \\
\hline & Both & 59 & 26.9 \\
\hline & I don't know & 75 & 34.2 \\
\hline \multirow{3}{*}{$\begin{array}{l}\text { Do you know that a } \\
\text { prosthodontist, a dental } \\
\text { specialist, deals with } \\
\text { maxillofacial prosthesis? }\end{array}$} & Yes & 40 & 18.2 \\
\hline & No & 179 & 81.7 \\
\hline & I don't know & 0 & 0 \\
\hline \multirow{2}{*}{$\begin{array}{c}\text { Have you heard of the } \\
\text { maxillofacial prosthodontics } \\
\text { branch of dentistry which deals } \\
\text { with the restoration of } \\
\text { maxillofacial defects with an } \\
\text { artificial substitute? }\end{array}$} & Yes & 24 & 10.9 \\
\hline & No & 195 & 89.1 \\
\hline \multirow{4}{*}{$\begin{array}{c}\text { If you have heard of it, where did } \\
\text { you hear about it? }\end{array}$} & Newspaper & 0 & 0 \\
\hline & Friends & 0 & 0 \\
\hline & Books & 18 & 8.2 \\
\hline & Dentist & 6 & 2.7 \\
\hline \multicolumn{4}{|c|}{ Table 1. Doctor's Awareness and Knowledge } \\
\hline
\end{tabular}

Amongst the $71 \%$ of practitioners who were aware of maxillofacial prosthesis, the commonest source of information was a dentist acquaintance (39.7\%) followed by friend (38.8 $\%$ ) and books (31.5 \%). $26.4 \%$ of medical practitioners had seen a patient with such defects rehabilitated with a prosthesis whereas $73.5 \%$ of practitioners had denied of the same. Only $2.3 \%$ of participants had referred such cases with maxillofacial defects for rehabilitation and had referred them to plastic surgeons with no follow up. $0.9 \%$ referred it for eye and ear prosthesis each and $0.5 \%$ for ear prosthesis, most of the participants referred the patients to plastic surgeons.
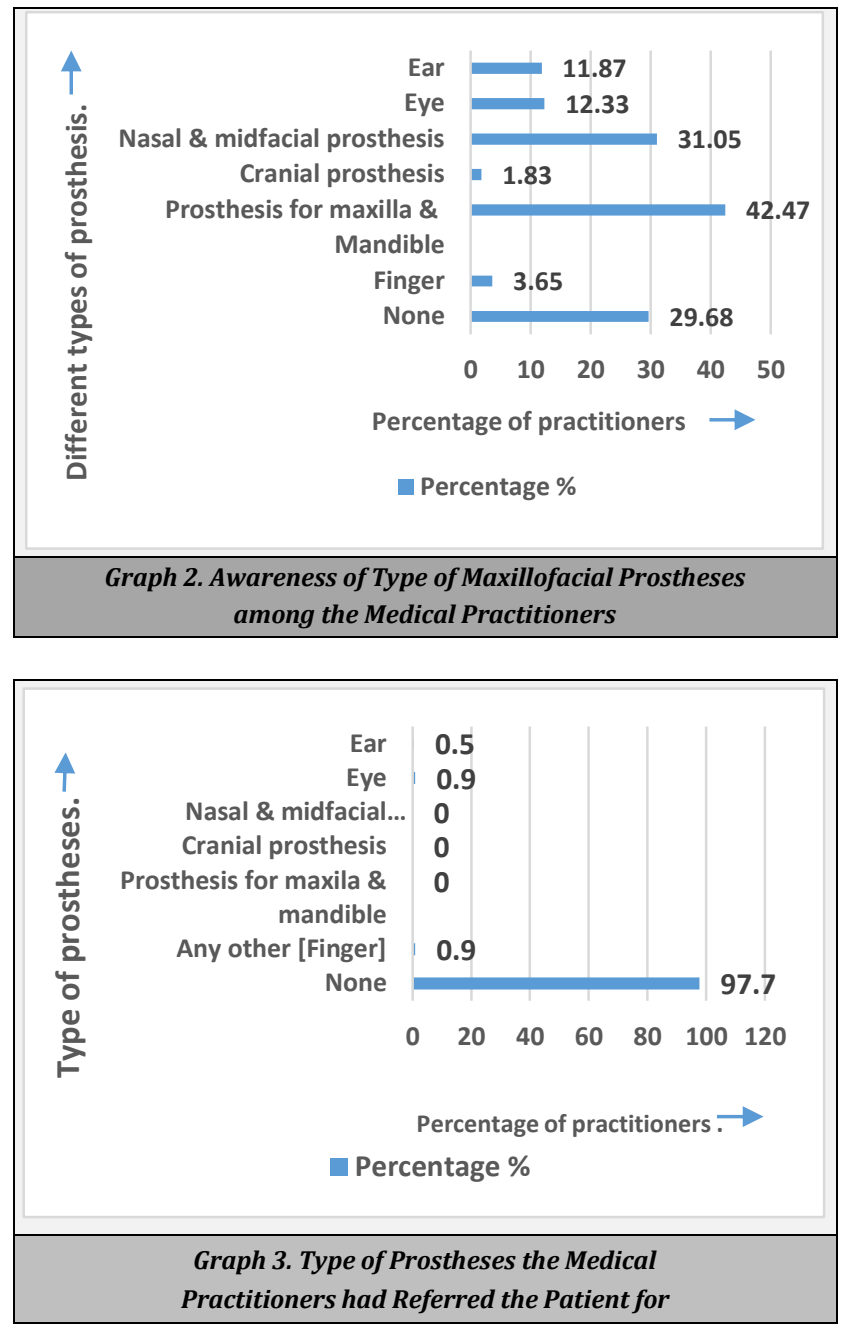

$19.2 \%$ of practitioners had knowledge about implant being used as retentive aid for maxillofacial prosthesis. Whereas $80.8 \%$ were not aware about it, and none of the practitioners knew about the average cost of a maxillofacial prosthesis. None of the practitioners were found of any idea about the cost of a maxillofacial prosthesis.

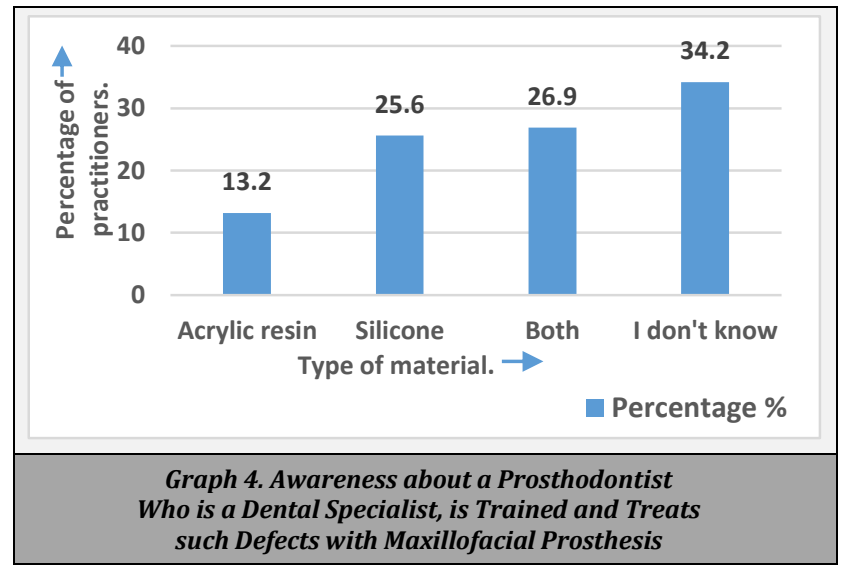

Most of the $18.2 \%$ were ophthalmologists having idea only about eye prosthesis. Out of $10.9 \%, 8.2 \%$ had read it in medical books sometime and only $2.7 \%$ had known it through dentist acquaintance. Positive response was obtained from about $40 \%$ of participants who wrote that this survey questionnaire itself brought new knowledge and they are keen onto seeking more. 
Percentage of practioners who responded to the question

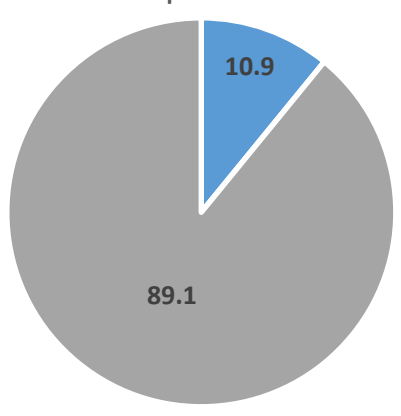

Graph 5. Awareness Regarding Maxillofacial Prosthodontics Being a Branch of Dentistry Which Deals with the Restoration of Maxillofacial Defects with an Artificial Substitute

\section{DISCUSSION}

Maxillofacial prosthodontics seeks to restore form and function of patients with head and neck defects, also extended appliances like finger prosthesis, vaginal stents and much more using removable prosthesis. Maxillofacial prosthodontists work as part of a multi-disciplinary team. They work closely with oral and maxillofacial surgeons, plastic surgeons, ear, nose and throat surgeons, ophthalmologists, general surgeons, general physicians, oncologists, orthopaedic surgeons, gynaecologists and paediatricians, speech therapists, occupational therapists and physiotherapists.

Ability and the scope of a Maxillofacial prosthodontist amongst the general public and the medical practitioners is scarcely understood. The practitioners are minimally aware of such a treatment modality and that it comes under the curriculum of a prosthodontist. On account of the lack of awareness, the patients with maxillofacial defects are not adequately guided and referred to a maxillofacial prosthodontist for rehabilitation.

Therefore, the present study was conducted as an attempt to collect the data regarding awareness and knowledge of the medical practitioners towards the maxillofacial branch of dentistry as a speciality to restore maxillofacial defects.

The observations of this study were as follows -

Nearly $52.1 \%$ of medical practitioners amongst 219 who were surveyed reported that they were aware of both congenital as well as acquired defects whereas, $29.7 \%$ informed that they did not have any knowledge of defects. (Graph 1)

Further questions addressed the awareness regarding types of prosthesis and their source of information. Various types of prostheses like ear, eye, nasal \& mid-facial prosthesis, cranial prosthesis, prosthesis for maxilla \& mandible or any other prosthesis like finger were known to the surveyed medical practitioners in various frequencies as shown in the table (Graph 2). Also, friends, their colleagues and textbooks were the common source of information. While $29.68 \%$ did not have any information about maxillofacial prosthesis.

When enquired that if any of the medical practitioners have personally come across a patient with maxillofacial defect ever in their practice, $70.3 \%$ of the practitioners denied for it and remaining $24 \%$ who witnessed such patients, belonged mostly to the department of ophthalmology and ENT associated with educational institutions. A large number of these practitioners belonged to the ophthalmology department as it is a common practice for them to use prefabricated eye shell which is readily available for immediate restoration of any ocular defect ${ }^{3}$. These prefabricated eye shells provide immediate restoration of the defect, but it does not restore the aesthetics and functionality in terms of support and movement which is quite possible in case of customised eye prosthesis.

Response to the next question revealed that only 5 [2.3\%] people amongst 219 practitioners have actually referred such patients with maxillofacial defects for rehabilitation (Graph 3). The defects were 2 patients with ocular defect, 1 with auricular defect and 2 for finger prosthesis and the practitioners were a part of departments of educational institutions / hospitals.

Patients with such kind of defects have adverse effects on the quality of life. The World Health Organisation (WHO) has defined quality of life (QoL) as "an individual's perception of his position in life in the context of the culture and value system in which he lives and in relation to his goals, expectations and standards and concerns." ${ }^{\prime 9}$ Mc Grouther ${ }^{10}$ concludes that even minor facial abnormalities can result in social stigma. Therefore, complete rehabilitation of the patient must be considered while planning treatment.

The recent advancement in the field of maxillofacial prosthodontics is the use of extraoral and intraoral implants for enhanced retention and support such types of prosthesis which is one of the most difficult and crucial factor to achieve during rehabilitation. When questioned about this, only 19.2 $\%$ of the practitioners were aware that the implants could be used to improve the prognosis of the prosthesis. Surprisingly, none of the practitioners had any idea regarding the average cost of maxillofacial prosthesis.

As far as the materials used for the fabrication of such prosthesis are concerned, $13.2 \%$ practitioners showed their knowledge regarding acrylic resin material, $25.6 \%$ people knew that it could be fabricated in silicone and $26.9 \%$ had idea of both.

$18.2 \%$ of the practitioners recognised prosthodontists to be a dental specialist who deals with maxillofacial prosthesis (Graph 4). These practitioners were the ones attached with the educational institutions associated with dental set-up from Departments of Ophthalmology and ENT. Private practitioners were not much aware. While, only $10.9 \%$ (Graph 5) of them knew that maxillofacial prosthodontics is the speciality dealing with rehabilitation of maxillofacial defects, their source of information being textbooks and dentists $8.2 \%$ and $2.7 \%$ respectively.

The survey reveals the percentage of awareness amongst the medical practitioners regarding various maxillofacial defects but at the same time it recognises the lack of awareness amongst them regarding a person who could be their colleague and be a part of multidisciplinary team which is responsible for addressing the need of patients' suffering with various kinds of maxillofacial defects.

Similar problem was documented by oral surgeons who are qualified in treating pathologies of craniofacial region have much less recognition amongst other medical colleagues. Navin et al. conducted a survey to assess the knowledge, attitude and awareness of the subject of oral and maxillofacial surgery amongst the consultants and practitioners of medicine in district of Vadodara and observed that few cases [like 
surgical removal of third molar, oral submucous fibrosis and implants] were the only problems where oral surgeons were preferred. For maxillofacial trauma and pathology, plastic surgeons; orthopaedic and ENT surgeons were preferred.11

In developed countries, the concept of a maxillofacial centre being an integral part of hospitals is a common finding. But this kind of approach towards rehabilitation of maxillofacial defects is very scarcely seen in India. Only in a few metropolitan cities a few health care centres have a maxillofacial unit wherein, a multidisciplinary team of medical and dental practitioners collaborate to deal with the maxillofacial cases.

\section{CONCLUSIONS}

Knowledge and awareness about maxillofacial prosthodontics as a specialty is poor. This probably is the reason why a patient in need of maxillofacial prosthesis could not find the correct doctor to treat his / her condition and remains without complete rehabilitation. The survey indicates a need to conduct awareness activities amongst the medical practitioners. An initiative to join hands to form a multidisciplinary team is required to improve the healthrelated quality of life of individuals with maxillofacial defects.

\footnotetext{
Limitations

The study is restricted to a small population, which restricted the information obtained about the awareness and knowledge of the maxillofacial branch of prosthodontics among the medical practitioners of Wardha city. The study was designed in a questionnaire format which is an indirect form of collecting information, other effective methods such as personal interactions and / or interviews could be undertaken.

Data sharing statement provided by the authors is available with the full text of this article at jemds.com.

Financial or other competing interests: None.

Disclosure forms provided by the authors are available with the full text of this article at jemds.com.
}

\section{REFERENCES}

[1] Dings JPJ, Merkx MAW, Maclennan-Naphausen MTPDC, et al. Maxillofacial prosthetic rehabilitation: a survey on the quality of life. J Prosthet Dent 2018;120(5):780-6.

[2] Pisulkar S, Pakhan AJ, Godbole SR. Psychological considerations in patients with maxillofacial defects: a literature review. Journal of School of Advanced Studies 2018;1(2):57-60.

[3] Belkhode V, Sathe S, Nimonkar SV, et al. Customized esthetic ocular prosthesis-a case report. Journal of School of Advanced Studies 2018;1(1):29-32.

[4] Beumer J, Curtis TA, Marunick MT. Maxillo facial rehabilitation: prosthodontic and surgical consideration. $2^{\text {nd }}$ edn. 1996.

[5] Rumsey N, Harcourt D. Body image and disfigurement: issues and interventions. Body Image 2004;1(1):83-97.

[6] Karthikeyan I. A review on prosthetic rehabilitation of maxillofacial region. Anaplastology 2014;3(1):1-5.

[7] Shinde DM, Godbole SR. Prosthetic rehabilitation of neurosurgical cranial defect using polymethylmethacrylate material-case report. Sch J Dent Sci 2019:4.

[8] Shaheed R, Shukla S, Acharya S, et al. Journey from fighters to survivors: quality of life and mental status in cancer patients in a rural tertiary care hospital. Journal of Clinical and Diagnostic Research 2019;13(8):1-4.

[9] Gondivkar SM, Bhowate RR, Gadbail AR, et al. Quality of life and oral potentially malignant disorders: critical appraisal and prospects. World J Clin Oncol 2018;9(4):569.

[10] Newton JT, Fiske J, Foote 0, et al. Preliminary study of the impact of loss of part of the face and its prosthetic restoration. J Prosthet Dent 1999;82(5):585-90.

[11] Shah N, Patel N, Mahajan A, et al. Knowledge, attitude and awareness of speciality of oral and maxillofacial surgery amongst medical consultants of vadodara district in Gujarat state. J Maxillofac Oral Surg 2015;14(1):51-6. 